\title{
Aprendendo ciências e matemática em um sítio arqueológico sob diversos olhares: das práticas de ensino ao ensino das práticas
}

Josilene Erlacher Werneck Falk josivida@hotmail.com

Secretaria de Estado da Educação - ES

Michele Pires Carvalho

michelepires.c@hotmail.com

0000-0002-7819-8489 Cariacica-ES

Thamires Belo de Jesus

Thamiresb@ifes.edu.b

0000-0001-6809-338

Instituto Federal do Espírito Santo

Kelly Araújo Ferreira Krauzer

kafbiologia@yahoo.com.br

0000-0002-7501-9414

Secretaria de Estado da Educação-ES

Carlos Roberto Pires Campos

Carlosr@ifes.edu.br

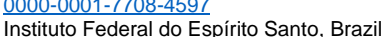

\section{RESUMO}

O trabalho destaca as aulas de campo como metodologia pedagógica para abordagem interdisciplinar de temas socioambientais, para ampliar a criticidade do olhar sobre o conhecimento e o ambiente. $O$ trabalho desenvolveu uma ação interdisciplinar, de modo a romper com o tratamento compartimentalizado e fragmentado do conhecimento, comumente presente nas escolas da educação básica. Trata-se de um estudo de caso, de natureza qualitativa, com procedimentos do tipo observação participante. 0 espaço de investigação foi um sítio arqueológico, um sambaqui, em Presidente Kennedy, Espírito Santo, o qual foi explorado por meio de determinação da poligonal e da análise dos elementos bióticos e antrópicos nele presentes. Como resultado, a atividade rompeu com paradigmas de uma educação tradicional, quando enfatizou a construção dos conhecimentos de forma colaborativa. Experienciar situações compartilhadas de troca e aprendizado com docentes das várias disciplinas é uma das formas de se superar o desafio da implementação das práticas pedagógicas interdisciplinares.
\end{abstract}

PALAVRAS-CHAVE: Práticas pedagógicas. Espaços educativos não formais. Sambaqui. 


\section{INTRODUÇÃO}

As tendências para educação científica, na atualidade, se constituem em grandes desafios a serem enfrentados pelos professores de ciências, quando tocam na questão de que a metodologia de ensino e o suporte teórico-pedagógico precisam estar ancorados em uma teoria da aprendizagem. Isso, porque o conhecimento é ativamente construído pelo aprendiz, não sendo, pois, somente repassado pelo professor. Essa perspectiva aponta para a relevância da abordagem sócio-cultural, aproximando a psicologia histórico-cultural de Vygotsky dos processos de aprendizagem fundados no desenvolvimento integral do educando, incluída, aí, a formação cidadã.

O ensino de ciências, segundo Cachapuz et al. (2009), depende de intensa renovação e precisa avançar nas questões relativas à cidadania, utilizando temas do cotidiano dos estudantes, de interesse social, os quais se associem a aspectos tecnológicos, sociais, culturais e econômicos. Tudo isso com o objetivo de propor reflexões sobre os diversos conhecimentos com vistas a uma formação crítica, que incentive o debate político, social e ambiental. Esta é uma preocupação em nível mundial, presente, sobretudo, no movimento CTSA (Ciência, Tecnologia, Sociedade e Ambiente).

Demo (2010), quando discorre sobre a educação científica, usa como parâmetro as exigências do mundo atual. Neste contexto, compreende que a necessidade dos indivíduos vai além da obtenção de acervos de conhecimento, os quais buscam, sobretudo, o desenvolvimento de habilidades diferenciadas, tais como a competência comunicativa, a habilidade para trabalhar em grupo, de forma interdisciplinar, em uma perspectiva cidadã. Assim, no ambiente formal escolar, a aprendizagem, por transmissão, de uma ciência fechada, com feitos científicos e conteúdos prontos e acabados, não condiz com as necessidades do mundo globalizado.

Partindo do pressuposto de que o espaço estritamente formal escolar não possui condições de acompanhar todos os avanços científicos e seus impactos na sociedade, como afirmam Krasilchik e Marandino (2007), defendemos que espaços não formais de educação, como instituições museais, reservas ambientais, ambientes naturais e culturais, podem ser fundamentais para o desenvolvimento de uma práxis pedagógica mediada e interdisciplinar. Nestes termos, a educação formal, utilizando-se de espaços não formais de educação (ENFE), amplia seus horizontes, favorecendo aos estudantes o contato direto com o fenômeno a ser investigado, oferecendo-lhes a possibilidade de agir em situações práticas, que culminem com reflexão, discussão e conscientização.

Outro elemento importante que valoriza o desenvolvimento de práticas pedagógicas em ENFE diz respeito à possiblidade de realização de um trabalho interdisciplinar, pois in loco os fenômenos naturais e culturais encontram-se entrelaçados, constituindo a realidade total do ambiente de estudo. Esta é uma outra mudança que precisa ser incorporada pela escola, porque a fragmentação do conhecimento, como afirma Morin (2003), a falta de diálogo entre as disciplinas, não permitem a construção de um estado de unidade. Para Morin (2003 p.38), é preciso unificar em vez de separar, já que vivemos submersos na complexidade do mundo. A fragmentação em ciências biológicas e humanas tem anulado a noção de vida e de homem, pois "unidades complexas, como o ser 
humano ou a sociedade, são multidimensionais: dessa forma, o ser humano é ao mesmo tempo biológico, psíquico, social, afetivo e racional".

Os espaços não formais de educação (ENFE) possuem, também, o condão, segundo Gohn (2011), de propiciar ações interativas entre os atores sociais, as quais são fundamentais para a aquisição de novos saberes, em que(GOHN, 2011 p .112):

O agir comunicativo dos indivíduos, voltado para o entendimento dos fatos e fenômenos sociais cotidianos, baseia-se em conviçç̃es praticas, muitas delas advindas da moral, elaboradas a partir das experiências anteriores, segundo as tradições culturais e as condições histórico-sociais de determinado tempo e lugar.

Dessa perspectiva, a aula de campo possibilita que o professor trabalhe, nesses espaços, com atividades que valorizem e problematizem temas da atualidade, tais como educação patrimonial, educação ambiental, diversidade entre outros. A aula de campo pode possibilitar uma abordagem diferenciada da que que seria empreendida apenas no ambiente escolar formal, caso de um sítio arqueológico, por exemplo, o qual se constitui em um ambiente culturalmente construído, dotado de múltiplas potencialidades temáticas.

Para Trilla (2008), os espaços educativos não formais devem ser tomados como ambientes complementares aos espaços escolares, cuja utilização relacionase a uma série de fatores sociais, econômicos e tecnológicos, de modo a atender a novas demandas educacionais que suscitam práticas pedagógicas extra-muros escolares e alternativas. Por se relacionarem com as questões sociais, os conhecimentos construídos em espaços não formais podem contribuir para a autonomia dos atores sociais, preparando-os para vida. Tanto Trilla (2008) quanto Gohn (2011) defendem os espaços não formais como coadjuvantes da formação cidadã, atuando, sobretudo como coadjuvantes da socialização e da autonomia.

Segundo Marandino et al. (2003), os espaços não formais proporcionam a utilização de diversas linguagens para a abordagem das temáticas propostas para o trabalho em seus ambientes, estabelecendo uma conexão entre os conhecimentos escolares e o contexto social. Para a autora, as limitações físicas e, às vezes, a falta de materiais, na escola, amplia a necessidade da utilização dos espaços não formais como complemento de práticas pedagógicas, com intuito de aproximação da teoria à realidade.

Assim compreendidos, os espaços educativos não formais contribuem para construção do conhecimento cientifico, pois propiciam ao educador a aplicação da ciência à leitura do social. As aulas de campo funcionam como metodologia pedagógica que transcorre de forma leve, lúdica e prazerosa, colaborando para a superação de medos. Em campo, não há hierarquia rígida, não há carteiras, secretaria, corpo técnico escolar. Em campo, trabalha-se em grupos, o professor orienta, medeia, discute. Os participantes sentem, cheiram, tocam, riem, participam das atividades e, ao final, verificam o que aprenderam. É no contato com o meio, na possibilidade de visualizar, de sentir, de interagir, que o indivíduo pode construir novos olhares, transformando o olhar do senso comum em um olhar mais crítico, apurado cientificamente.

A educação não formal trazida por Gohn (2011) tem como meta o aprender a conviver com a diversidade, socializando-se com adaptação do grupo a diferentes 
culturas e com a construção da identidade coletiva de um grupo. Além de se preocupar com a reconstituição da memória e da identidade local, a educação não formal contribui para desenvolver vínculos sociais, favorecendo a apropriação e a ressignificação de espaços públicos.

\section{A MEDIAÇÃO NOS ESPAÇOS EDUCATIVOS NÃO FORMAIS}

Vygotsky fundamenta-se no materialismo dialético, que confere a sua teoria uma perspectiva histórico-cultural por meio da qual, Scalcon (2002 p.51) ressalta que,

[...] o homem é um ser histórico que se constrói através de suas relações como o mundo natural e social. Mais do que isso, é um homem que se diferencia como espécie pela capacidade de transformar a natureza através de seu trabalho, por meio de instrumentos por ele mesmo criados e aperfeiçoados ao longo do desenvolvimento histórico humano.

Vygotsky, (2005, 2007), ao conceber o social como o princípio da aprendizagem, defende que toda relação do indivíduo com o mundo se processa por meio de instrumentos, técnicas e linguagem. Assim, ao estudar os mecanismos psicológicos do ser humano, identificou que o desenvolvimento das funções psicológicas superiores ocorrem por meio de processos de mediação, caracterizados pela relação do homem com o mundo, bem como com outros homens, postulando que esta relação é mediada por instrumentos e signos. A partir dessa reflexão, o instrumento pode ser compreendido como algo (OLIVEIRA, 2008, p. 29)

[...]entre o trabalhador e o objeto de seu trabalho, ampliando as possibilidades de transformação da natureza. Ele carrega consigo, portanto, a função para o qual foi criado e o modo de utilização desenvolvido durante a história do trabalho coletivo. É, pois um objeto social e mediador da relação entre o indivíduo e o mundo.

Partindo do pressuposto de que o ensino de ciências pode ocorrer em diversos contextos educacionais e espaciais, defenderemos que uma aula de campo em ENFE pode colaborar para a formação do aluno cidadão, visto que, pautado em pressupostos histórico culturais, em contato com o meio, com a historicidade, de forma interativa, manipulando instrumentos, sob intervenção do professor, o trabalho em campo pode desenvolver nos atores escolares um olhar crítico sobre a realidade, ajudando-os a relacionar o conhecimento científico com seu cotidiano.

Neste sentido, a importância da aula de campo reside no fato de possibilitar o contato dos estudantes com inúmeras vivências que podem se tornar em um conhecimento significativo, corroborado pelas interações com objetos de aprendizagem e com as relações estabelecidas entre as pessoas e o meio.

Muitos trabalhos têm sido publicados em diversos eventos apontando as vantagens desse tipo de metodologia de ensino, entre os quais citamos Oliveira e Correia (2013); Santos, Bezerra, Firmino e Rangel (2013) e Seniciato e Cavassan (2004). Entretanto, sair da sala de aula, levar alunos para espaços não formais e continuar a trabalhar de forma expositiva não significa alcançar o caráter inovador apontado por tais estudos no ensino de ciências. De acordo com Viveiro e Diniz 
(2009), é importante que a atividade de campo não compreenda só a saída, mas todas as outras etapas como o planejamento, a execução, a exploração dos resultados e a avaliação.

A pesquisa de Albuquerque, Angelo e Dias (2012) destaca que um trabalho de campo, realizado dentro de um contexto metodológico organizado, estimula a produção de um conhecimento crítico. Oliveira e Gastal (2009) afirmam que o processo de ensino aprendizagem pode ter sua eficácia melhorada quando o conhecimento trabalhado se torna mais facilmente assimilável pelo aluno.

Dessa forma, pretendemos defender nesse trabalho, de uma perspectiva histórico-cultural, as aulas de campo como uma metodologia pedagógica interdisciplinar capaz de favorecer diálogos para a construção do saber de forma interativa, ultrapassando a compartimentalização das fronteiras entre as disciplinas curriculares.

Segundo os Parâmetros Curriculares Nacionais, a interdisciplinaridade seria "utilizar os conhecimentos de várias disciplinas para resolver um problema concreto ou aprender determinado fenômeno sob diferentes pontos de vista" (1999 p. 34-36). O documento valoriza os saberes úteis, no caso deste relato de experiência, Educação Patrimonial, a qual se configura como um problema contemporâneo, relacionado à questão da memória. Assim, a abordagem interdisciplinar possui um caráter relacional, isto é, por meio de uma prática pedagógica estabelecem-se interconexões entre os conhecimentos de disciplinas, e os professores condutores da prática pedagógica, devem procurar dar sentido à prática educativa, integrando e articulando as disciplinas. A proposta interdisciplinar não busca a eliminação das disciplinas, mas deve torná-las comunicativas entre si, compreendendo-as como processos históricos e culturais, razão pela qual precisam ser atualizadas. $O$ trabalho interdisciplinar favorece que todos ensinem, aprendam e questionem, superando olhares fundamentalistas.

O potencial das aulas de campo, em ensejar uma abordagem interdisciplinar, se justifica em face da complexidade dos temas, aqui, no caso, o tema gerador foi conhecer, delimitar e proteger um sítio arqueológico já em estágio bastante fragilizado advindo das ações antrópicas. O tema Educação Patrimonial é comum a todas as disciplinas e sua discussão implica participação social, troca de ideias e construção de conhecimento. A interdisciplinaridade possibilita que a articulação das ações explicite sentidos velados, atualize ideologias, como, por exemplo, que a América Portuguesa, antes da chegada dos colonizadores, só era habitada por guaranis; ou construa novos sentidos, como por exemplo, que nossos homens préhistóricos detinham tecnologias para domesticação do espaço e possuíam sociabilidades em função de corpos d'água.

\section{PERCURSO METODOLÓGICO E A EXPERIÊNCIA EM UM SAMBAQUI}


Trata-se de uma formação continuada de professores de ciências, desenvolvida por meio de uma aula de campo, realizada no dia 29 de junho de 2013, em um sambaqui, sitio arqueológico pré-histórico, característico de ambientes costeiros, localizado na bacia sedimentar adjacente ao rio Itabapoana em Presidente Kennedy, no sul do Espirito Santo. Participaram da ação, 23 (vinte e três) professores da educação básica das disciplinas de Matemática, Biologia, Química, Física, Geografia e pedagogo. Todos os professores-alunos, participantes da prática pedagógica, compunham o corpo discente do Programa de PósGraduação em Educação em Ciências e Matemática do IFES. A exceção dos geógrafos e biólogos, metade dos participantes nunca havia tomado parte em uma aula de campo, nunca havia procedido a uma intervenção pedagógica em um espaço não formal. A faixa etária média dos participantes girava em torno dos trinta anos. Conduziram a prática pedagógica dois professores do programa de Pós-Graduação em Educação em Ciências e Matemática do IFES, sendo sua formação em ciências humanas e engenharia. Ambos atuam na Educação Superior há mais de quinze anos e possuem vasta experiência na formação de professores de ciências. Os conteúdos explorados em campo deveriam girar em torno do tema gerador: conhecer, delimitar e proteger o Sambaqui Campinas 1. Assim, os conteúdos dentro desse tema eram: trigonometria, Alcalinidade e acidez de solos, a restinga capixaba, bacias sedimentares, pré-história brasileira.

Para Silva; Silva; Varejão, (2010), as aulas de campo podem ser consideradas caminhos alternativos para a construção do conhecimento. Os autores ainda ressaltam a importância dos três momentos de planejamento necessários para que tal estratégia tenha sucesso, o pré-campo, o campo e o pós-campo. Este processo é importante, pois propiciará maior interação entre os alunos, destacando que, em campo, a todo momento, relaciona-se teoria e prática: [...] O trabalho de campo objetiva trazer ao aluno um olhar crítico sobre a realidade e a teoria compreendendo-a dialeticamente (SILVA; SILVA; VAREJÃO, 2010, p. 188).

As aulas de campo não devem servir para repetição de conhecimentos, mas para uma construção científica, tendo em vista seus vários papeis didáticos, por exemplo, aplicar um conhecimento aprendido em espaço formal, aprender um conhecimento novo, comparar abordagens, incentivar a produção de conhecimento na leitura da realidade entre outros. $O$ importante é que não haja desconexão com o conjunto de matérias, ou seja, os conteúdos estão dentro de uma mesma rede de saberes e os alunos só constroem conhecimentos quando estes saberes são apresentados de forma interdisciplinar, não fragmentada.

As três etapas necessárias para o trabalho de campo são, assim, apresentadas por Silva; Silva; Varejão, (2010).

Pré-campo: Etapa considerada fundamental para situar o aluno com apresentação de roteiros, objetivos da aula e finalidade daquele estudo.

Campo: Precisa ser visto pelos alunos como um lugar de discussão e compreensão da prática relacionada às teorias discutidas em sala de aula. Deve-se estimular a curiosidade, o respeito de opiniões, a percepção e os debates. 
O objetivo da investida de campo foi trabalhar diferentes práticas de ensino, sob diferentes olhares, interagindo conteúdos de três disciplinas, a fim de um propósito maior: o conhecimento e a delimitação do sítio arqueológico, visando a explorar a região sem danificar ou intervir fisicamente na mesma, a fim de contribuir para sua preservação. Nesse trabalho, temas socioambientais também vieram à tona. Para tanto, foram utilizadas as seguintes ferramentas para a realização da prática: trena, teodolito caseiro, GPS (Sistema de Posicionamento Global), máquina fotográfica, tripé, estacas e pranchetas, conforme figura 1 a seguir.

Figura 1: Ferramentas utilizadas no campo

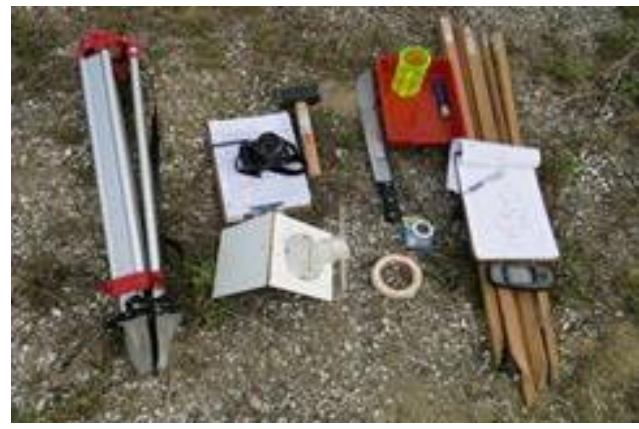

(Fonte: Arquivo dos pesquisadores)

O teodolito caseiro é um instrumento utilizado para medir ângulos (verticais e horizontais), confeccionado com um transferidor de 360, um canudo de sorvete, um copo de requeijão e uma superfície rígida para apoio como um pedaço de madeira ou papelão. Este instrumento pode ser confeccionado pelos próprios alunos durante as aulas de matemática ou geografia. Na ocasião foi confeccionado o teodolito caseiro conforme figura 2 a seguir.

Figura 2: Teodolito caseiro

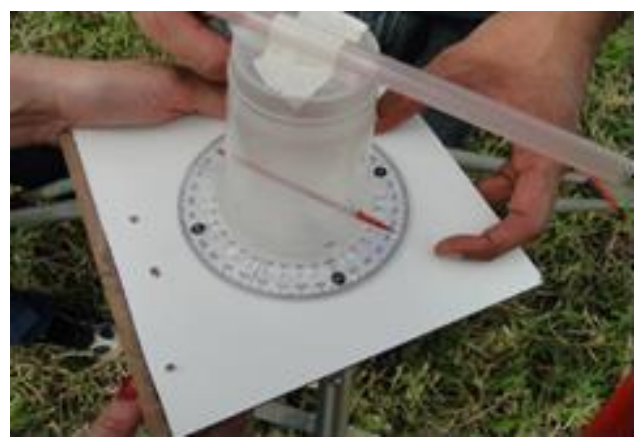

(Fonte: Arquivo dos pesquisadores)

Neste trabalho, foi utilizada a metodologia do tipo etnográfica, razão pela qual apresentamos a descrição da prática pedagógica entremeada por comentários advindos dos próprios pesquisadores que dela participaram e dos relatos feitos 
pelos outros participantes, os quais foram anotados em seus diários de campo. A análise dos dados obtidos das entrevistas diretas, ocorridas no pós campo com os fins de avaliação e debate sobre a prática pedagógica, foi feita no item resultados e discussões, da perspectiva das considerações teóricas apresentadas, quais sejam, a teoria sócio-interacionista, a educação não formal e a interdisciplinaridade.

\section{RESULTADOS E DISCUSSÕES}

A aula de campo foi realizada no sítio arqueológico pré-histórico, intitulado Sambaqui Campinas 1. Os sambaquis são sítios arqueológicos construídos com material malacológico, gastrópodes e bivalves, de estratigrafia complexa, estruturado de modo contínuo por deposição das conchas, podendo conter sedimentos arenosos ou argilosos e algum material faunístico, tais como ossos de peixes, de mamíferos e aves, advindos de atividades culturais diversificadas tais como, rituais de sepultamento, de re-sepultamento ou outras rotinas da vida social. O termo sambaqui caracteriza sítios arqueológicos situados às margens de grandes cursos d'água, tais como lagunas, desembocaduras de rios e manguezais, constituindo-se plataformas secas que se destacam no panorama. A paisagem composta por sambaquis constitui-se, ela mesma, cultura material, patrimônio de todos os brasileiros, legítima representante da memória pré-histórica nacional (GASPAR, 2000; CARVALHO et al. 2013). Na aula de campo, foi possível explorar diferentes práticas de ensino, e diferentes conteúdos de trigonometria, geometria, semelhança de triângulos, perímetro e área, distâncias, coordenadas do plano, sistemas de posicionamento, noções de lateralidade e espaço, estudos cartográficos, características físicas e químicas de materiais geológico do solo, características de fauna e flora da restinga, povoamento da costa brasileira, preservação ambiental e educação patrimonial.

Também foi trabalhado o ensino considerando outros tipos de conteúdos como os procedimentais, ao incentivar o uso de diversos instrumentos para desempenhar diferentes práticas, como a utilização do GPS, do teodolito e da trena, a construção do teodolito. O trabalho em equipe demonstrou uma outra dimensão, a dos conteúdos atitudinais. Inicialmente, fizemos o reconhecimento do local a ser delimitado com o objetivo de verificar sua extensão. O objetivo era construir uma poligonal conforme ilustrada na figura 7. Após o reconhecimento do espaço, procedemos à identificação dos vértices da poligonal e, nestes pontos, colocamos as estacas (fig. 3).

Orientaram o trabalho as questões: Como determinar a distância entre os vértices da poligonal? Como determinar o ângulo exato entre os vértices? As respostas às indagações nos conduziram a práticas de ensino que pudessem abarcar os conteúdos listados anteriormente e direcionar para práticas de delimitação de poligonais realizadas por profissionais da topografia ${ }^{1}$.

Figura 3: Estaqueamento da área

\footnotetext{
${ }^{1}$ É a ciência que estuda e determina analiticamente as medidas de área e perímetro, localização, orientação, variações no relevo e
}

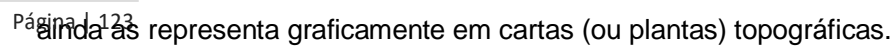




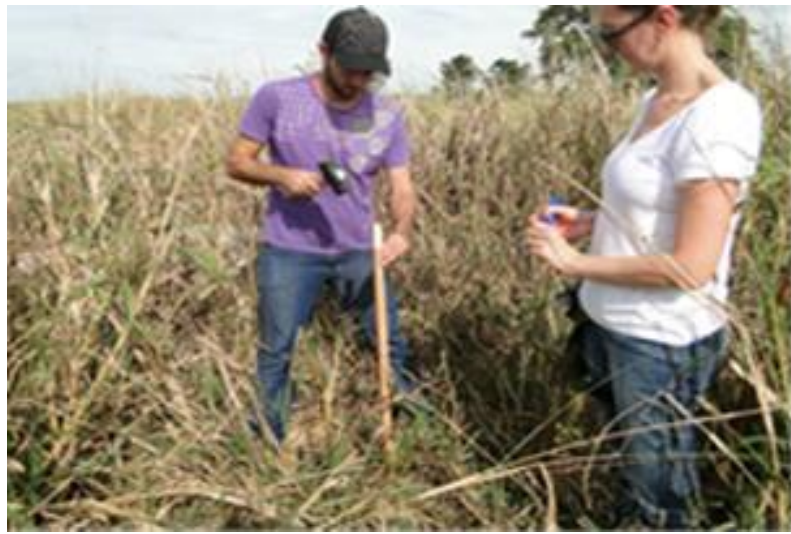

Fonte: Arquivo dos pesquisadores

Uma vez fincadas todas as estacas nos limites do terreno a ser mapeado, iniciamos a delimitação da poligonal. A delimitação compreende o processo de determinar o comprimento dos lados e o ângulo interno $(\alpha)$ formado pelos lados (fig. 4).

Figura 4: Ângulo de uma poligonal

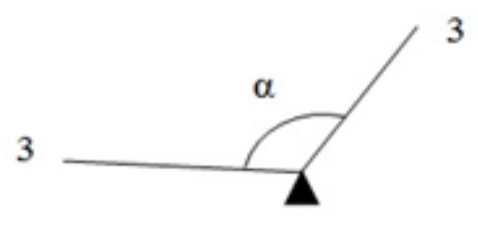

(Fonte: Arquivo dos pesquisadores)

Inicialmente, posicionamos o teodolito no ponto 2, apontamos para o ponto 3 e "zeramos" a medição, ou seja, apontamos a marcação zero grau para o ponto 3 , depois giramos o teodolito até que a mira chegasse ao ponto 3 , conforme figura 3. 


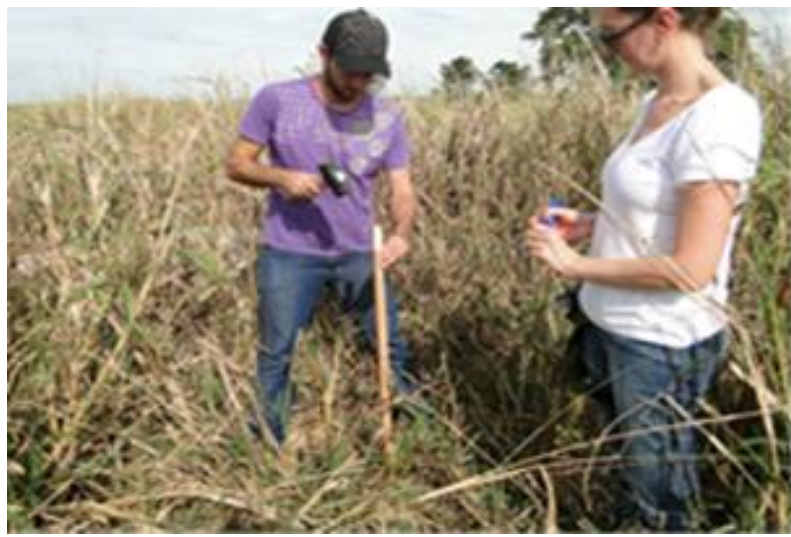

(Fonte: Arquivo dos pesquisadores)

Com esta prática, trabalhamos o conceito de tipo de ângulos e trigonometria. Uma vez determinado o ângulo $\alpha$, medimos a distância entre os pontos 1 e 2 e depois entre os pontos 2 e 3, com o auxílio de uma trena de 50 metros, com isso determinamos a medida dos lados, como ilustra a figura 4, processo repetido em todos os vértices da poligonal, demarcado pelas estacas.

Figura 6: Medindo a distância entre as estacas

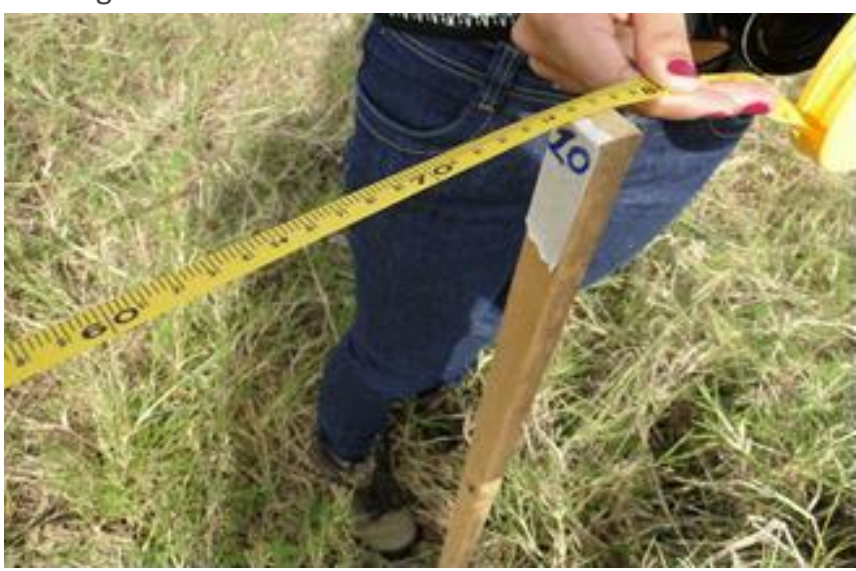

(Fonte: Arquivo dos pesquisadores)

Como forma de registrar a localização geográfica de cada ponto, utilizamos o GPS, o qual nos forneceu as coordenadas geográficas de cada ponto em um sistema de latitude e longitude (Tabela 1). Com esta prática foi possível trabalhar os conceitos de localização espacial e de lateralidade, visto que era possível estabelecer estimativas para as coordenadas de cada ponto a serem calculadas pelo GPS, com base na sua localização. 


\begin{tabular}{l|l|l}
\hline & \multicolumn{2}{l}{ COORDENADAS } \\
\hline PONTOS & LATITUDE & LONGITUDE \\
\hline 1 & $21^{\circ} 12^{\prime} 38.47^{\prime \prime} \mathrm{S}$ & $41^{\circ} 3^{\prime} 28.32^{\prime \prime} \mathrm{O}$ \\
\hline 2 & $21^{\circ} 12^{\prime} 38.59^{\prime \prime} \mathrm{S}$ & $41^{\circ} 3^{\prime} 28.71^{\prime \prime} \mathrm{O}$ \\
\hline 3 & $21^{\circ} 12^{\prime} 38.48^{\prime \prime} \mathrm{S}$ & $41^{\circ} 3^{\prime} 28.84^{\prime \prime} \mathrm{O}$ \\
\hline 4 & $21^{\circ} 12^{\prime} 38.75^{\prime \prime} \mathrm{S}$ & $41^{\circ} 3^{\prime} 29.21^{\prime \prime} \mathrm{O}$ \\
\hline 5 & $21^{\circ} 12^{\prime} 38.69^{\prime \prime} \mathrm{S}$ & $41^{\circ} 3^{\prime} 29.31^{\prime \prime} \mathrm{O}$ \\
\hline 6 & $21^{\circ} 12^{\prime} 38.97^{\prime \prime} \mathrm{S}$ & $41^{\circ} 3^{\prime} 29.77^{\prime \prime} \mathrm{O}$ \\
\hline 7 & $21^{\circ} 12^{\prime} 39.61^{\prime \prime} \mathrm{S}$ & $41^{\circ} 3^{\prime} 29.39^{\prime \prime} \mathrm{O}$ \\
\hline 9 & $21^{\circ} 12^{\prime} 39.42^{\prime \prime} \mathrm{S}$ & $41^{\circ} 3^{\prime} 29.12^{\prime \prime} \mathrm{O}$ \\
\hline 10 & $21^{\circ} 12^{\prime} 39.26^{\prime \prime} \mathrm{S}$ & $41^{\circ} 3^{\prime} 29.12^{\prime \prime} \mathrm{O}$ \\
\hline 11 & $21^{\circ} 12^{\prime} 39.20^{\prime \prime} \mathrm{S}$ & $41^{\circ} 3^{\prime} 28.82^{\prime \prime} \mathrm{O}$ \\
\hline 12 & $21^{\circ} 12^{\prime} 38.96^{\prime \prime} \mathrm{S}$ & $41^{\circ} 3^{\prime} 28.60^{\prime \prime} \mathrm{O}$ \\
\hline 13 & $21^{\circ} 12^{\prime} 38.99^{\prime \prime} \mathrm{S}$ & $41^{\circ} 3^{\prime} 28.45^{\prime \prime} \mathrm{O}$ \\
\hline & $21^{\circ} 12^{\prime} 38.75^{\prime \prime} \mathrm{S}$ & $41^{\circ} 3^{\prime} 28.27^{\prime \prime} \mathrm{O}$ \\
\hline
\end{tabular}

Ao determinar todos os ângulos internos e o comprimento dos lados, enfim, delimitamos a poligonal que determina os limites do sítio arqueológico. Após registar todos os pontos que constituem a poligonal, utilizamos o software Google Earth, programa gratuito, para localizar a poligonal por meio de uma imagem de satélite, conforme imagem seguinte (Fig. 7).

Figura 7: Representação da poligonal no Google Earth

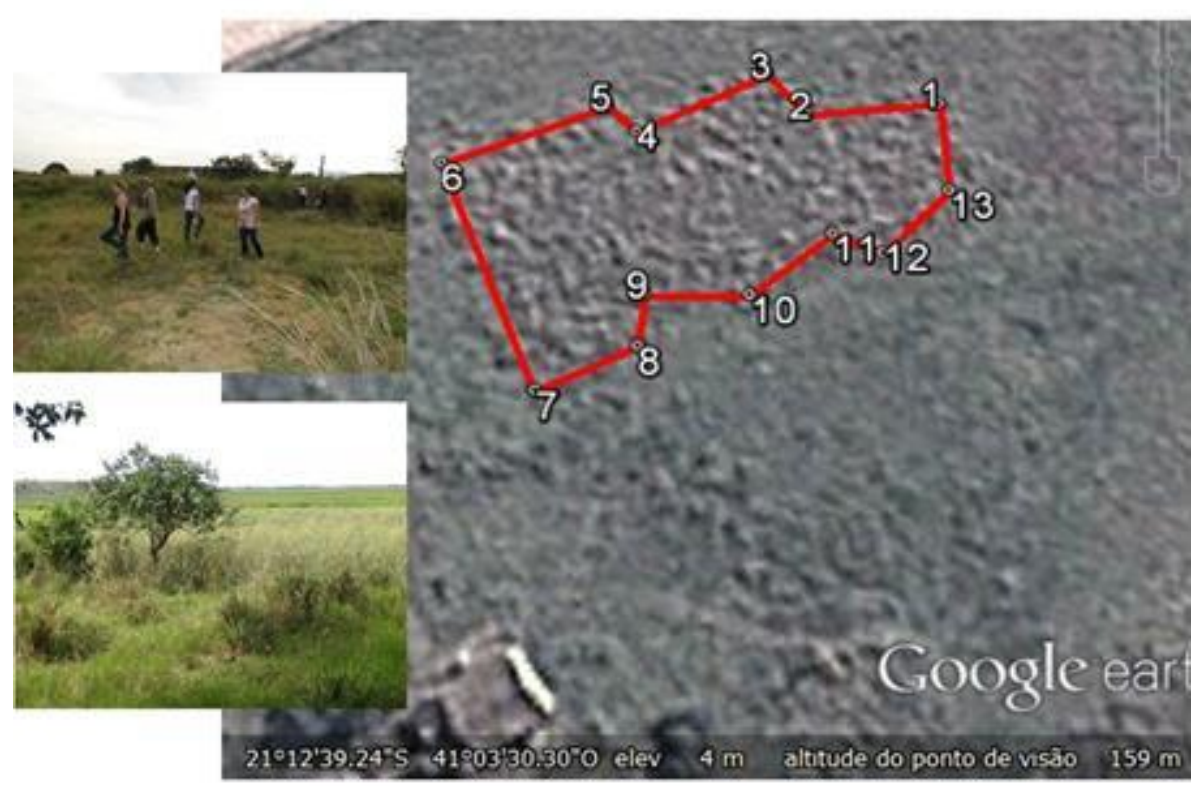

(Fonte: Arquivo dos pesquisadores; Google Earth) 
É importante ressaltar que as medidas encontradas possuem uma margem de erro considerável, visto que o instrumento utilizado para medida dos ângulos, o teodolito, é um instrumento caseiro, que possui suas limitações. Entretanto, o próprio conceito de estimativas e margem de erros são conteúdos importantes a serem trabalhados numa prática como essa.

Após determinação a área do sítio, foram coletadas pequenas amostras de solos de diferentes pontos, que foram etiquetadas com a localização da coleta e depois caracterizados segundo análise granulométrica, tais como tipos de sedimentos, esfericidade, que indica o seu transporte, tamanho, seleção e coloração segundo Tabela Munsell, para isso, foram utilizadas, colheres de café e sacos coletores de solo. Trabalhamos com uma escala granulométrica elaborada pelo LAGESED da UFRJ.

Considerando os conhecimentos da área biológica, um dos aspectos que foram analisados pelos participantes da aula no sítio arqueológico corresponde à caracterização da fauna, flora da restinga capixaba e da degradação ambiental sofrida pelo ambiente.

Os participantes também puderam exercitar a metodologia da classificação de grupos biológicos encontrados no sítio com auxilio de chaves de classificação, uma atividade que foi executada de forma prática, a qual, em sala de aula, os professores trabalham normalmente de forma abstrata ou apenas teórica.

$\mathrm{Na}$ investida de campo, os professores-alunos puderam observar a degradação ambiental da região, que sofre ação antrópica decorrente da exploração de recursos naturais. Além disso, foi possível perceber o descaso com sítios arqueológicos. O Sambaqui Campinas 1, por exemplo, somente possui, segundo relato de moradores, $20 \%$ do que já foi um dia. A utilização das conchas como base para pavimentação de vias vicinais e como matéria prima para a cal devastou pelo menos mais da metade dos sambaquis do sul capixaba.

Outro fator relacionado à degradação ambiental foi direcionado para o solo, - qual foi analisado em relação a sua granulometria e características organolépticas, inserido, conhecimento da área de geologia e dos cuidados necessários no usufruto e na conservação de espaços de sítios arqueológicos.

Ao coletar pequenas amostras de solo e realizar o teste com ácido clorídrico, conseguimos identificar o potencial de carbono contido, o que atesta ações culturais. Trata-se de testes simples que ajudam a ampliar a compreensão de tempo, espaço e história, pois as reações químicas dos testes realizados nos materiais coletados podem explicar fenômenos naturais que aconteceram ao longo de tempo naquela região.

As atividades propuseram uma intima ligação entre os saberes geológicos, químicos, históricos e biológicos, ultrapassando o caráter meramente disciplinar, propondo um olhar sobre a ciência a partir de sua complexidade. A perspectiva dialógica na abordagem dos conteúdos não só integrou os objetos de estudo das disciplinas como também aproximou os professores na discussão dos temas. Estas são as duas condições para um trabalho interdisciplinar, integração dos conteúdos e trabalho colaborativo para aproximar os professores. Em relação aos aspectos geográficos da região, os participantes puderam analisar os tipos de relevo que a compõem, conhecer o processo de formação de uma bacia sedimentar, estudar a diferença entre intemperismo e erosão e como ocorre a formação de ambientes 
de sedimentação, compreendendo a importância dos rios neste processo geológico.

Por meio das situações encontradas em campo também foi possível problematizar, ou criar espaços para resolução de problemas a serem trabalhados pelos alunos, trazendo a criticidade como elemento componente de conteúdos atitudinais, elemento relevante para formação cidadã. Isso ocorreu na hora dos caminhamentos sistemáticos pela área. Não é possível fazer uma investida de campo sem caminhar pela área e observar a paisagem, sua configuração, sua morfologia e sua dinâmica. Esse trabalho exigiu atitude científica por parte de professores e professores-alunos.

O trabalho de exploração do sítio arqueológico de forma interdisciplinar permitiu que as disciplinas de matemática, geografia e ciências dialogassem em favor da interligação dos conhecimentos. Na discussão ocorrida no pós-campo, ao avaliarem a possibilidade de replicação da prática pedagógica em suas escolas, a maioria dos professores concordou que seria possível, apesar dos entraves burocráticos, pois uma aula de campo movimenta todo o corpo técnico e administrativo da escola. Algumas inferências observadas decorrem da participação dos professores-alunos em um trabalho, o qual buscou delimitar um sitio arqueológico sobre o qual não havia literatura produzida na área específica. Alguns perguntaram se o trabalho poderia ser enviado ao IPHAN ou à Secretaria de Cultura, tendo em vista sua relevância social. Um pedagogo presente mencionou que a metodologia da aula de campo permitiu a abordagem tanto do tema educação patrimonial quando dos conteúdos científicos por meio de diferentes recursos e do dinamismo das estratégias, tais como a divisão dos grupos e o compartilhamento de informações, o que contribuiu para o aprendizado de vários conteúdos. Entre os quais os participantes citaram a relação entre geometria e trigonometria, o que se constituía em um desafio para alguns docentes, a diferença entre intemperismo e erosão e, por último, como avaliar o Ph de um solo.

Uma outra evidência que deve ser citada, a qual aponta para a aprendizagem efetiva dos sujeitos participantes, adveio de um depoimento de um biólogo presente no grupo, o qual mencionou que ela mesma aprendeu muito sobre trigonometria, sobre percepção e sensorialidade a partir do olhar sobre a paisagem cultural. Ao observar a modificação do espaço, ela pode desconstruir concepções alternativas que ainda persistiam sobre o tema, como por exemplo, a ideia de que antes da chegada de Cabral ao Brasil só havia índios guaranis. A maioria dos professores nem sabia da existência da pré-história brasileira e, de início, confundiam índios com sambaquieiros. Após a aula de campo, começaram a perceber a diferença, sobretudo, a partir de duas características culturais, os sambaquieiros não eram agricultores e também não produziam cerâmica, marcas fulcrais da cultura guarani. Aprendizagens assim deixaram os professores extremamente motivados para desenvolver aquelas atividades em sala de aula, com seus alunos. Alguns professores afirmaram que se eles estavam espantados com o que aprenderam, imagine seus alunos, que são naturalmente curiosos e entusiasmados. A experiência de atuar como arqueólogo em campo, na reconstituição dos fragmentos da pré-história brasileira é fator motivante, ainda que esta reconstituição parta, somente, da leitura crítica da paisagem domesticada. 
Além disso, em uma experiência como a descrita, as ciências escolares são relacionados ao próprio ambiente de ação. É, portanto, por meio da interação entre sujeito aprendiz e objetos de conhecimento, mediada pelos instrumentos de aprendizagem, que os olhares críticos são construídos.

\section{CONSIDERAÇÕES FINAIS}

Os espaços de educação não formal podem servir de palco para ações pedagógicas que auxiliem na ampliação de conceitos e na construção do conhecimento por meio da interação com os objetos que os constituem e que estimulam a aprendizagem, descrita por Vygotsky, como importante forma de compreensão do mundo e como sobre ele atuar. Os instrumentos utilizados em uma aula de campo em um EENF possibilitam que diferentes práticas de ensino sejam executadas.

As práticas realizadas no campo, como a delimitação da poligonal, promoveram uma leitura crítica e interativa dos participantes com o ambiente, possibilitando a produção de conhecimentos que não existiam. Estes conhecimentos, por sua vez, possibilitaram a criação de sujeitos mais críticos e conscientes das potencialidades de ensino utilizando-se um EENF. É, portanto, por meio deste olhar crítico que um sujeito será capaz de relacionar o conhecimento científico com o conhecimento adquirido nas experiências, tornando-se sujeito de seu próprio conhecimento. A complexidade do ambiente, culturalmente transformado, demandou da interdisciplinaridade a produção de novos conhecimentos por meio de práticas pedagógicas investigativas, por meio das quais os participantes, intervindo e colaborando para produção de algo cientificamente novo, atuaram como cientistas em campo. Tais atividades possibilitam avanços para alguns dos problemas sociais, entre os quais a devastação provocada pela ação antrópica. $\mathrm{O}$ trabalho também buscou ampliar o conhecimento sobre assentamentos humanos pré-históricos na costa capixaba e contribuir para sua incorporação à identidade sul capixaba e à sua consequente preservação.

Pensar em uma prática pedagógica como as aulas de campo em ambientes naturais significa defender uma ação educativa crítica, reflexiva e até emancipatória, tendo em vista o fato que a prática pedagógica pode lançar luz na análise e discussão das problemáticas ambientais e culturais do mundo atual da perspectiva interdisciplinar, quais sejam, a preservação do meio ambiente e a preservação da memoria e suas evidências materiais e imateriais. 


\title{
Learning sciences and mathematics in an archaeological site from different perspectives: an approach about the interdisciplinary pedagogical practices
}

\begin{abstract}
The paper approaches the importance of field classes, highlighting how they can foster a critical look at the everyday and scientific knowledge. The research developed an interdisciplinary action, in order to break with the compartmentalized and fragmented treatment of knowledge, commonly present in primary schools. This is a qualitative study with procedures characteristic of participant observation. The research area took place in an archaeological site consisting of a shell mound in Presidente Kennedy, Espírito Santo State, Brazil. The practice was developed by the subjects in an interdisciplinary way, being the archaeological site explored by determining the polygonal and the analysis of biotic elements of the environment. The experience broke with traditional paradigms of education, emphasized a critic way of building the knowledge. We concluded that experiencing shared situations of exchange and learning with teachers of the various disciplines is one of the ways to overcome the challenge of implementing interdisciplinary pedagogical practices.
\end{abstract}

KEYWORDS: Pedagogical practices. Non-formal educational settings. Shell mounds. 


\section{REFERÊNCIAS}

ALBUQUERQUE, Maria Adailza Martins; ANGELO, Maria Deusia Lima; DIAS, Angélica Mara de Lima. Proposta de aula de campo: e estudo do meio complexo Xingó. Geotemas, Pau dos Ferros, Rio Grande do Norte, v.2,n.1, p.111-128, 2012

BRASIL. Ministério da Educação, Secretaria de Educação Média e Tecnológica. Parâmetros curriculares nacionais: ensino médio. Brasília: Ministério da Educação, 1999.

CACHAPUZ, António et al. A Necessária Renovação do Ensino das Ciências. 2. ed São Paulo: Cortez, 2009. 263 p.

CARVALHO, M. et al. Ciências e arte no sambaqui: uma experiência à luz das teorias da complexidade e do sociointeracionismo. In: IX ENPEC, 2013 Aguas de Lindoia, Anais ... ABRAPEC, Rio de Janeiro: Nutes/UFRJ disponível em www.nutes.ufrj.br/abrapec/ixenpec/atas/resumos/R1643-1.pdf acessado em $15 / 01 / 2017$

DEMO, Pedro. Educação Científica. 2010. B. Téc. Senac: a R. Educ. Prof., Rio de Janeiro, v. 36, n.1, jan./abr. 2010.. Disponível em:

<www.senac.br/BTS/361/artigo2.pd>. Acesso em: 02 jun. 2013.

GASPAR, M.D. Sambaqui: arqueologia do litoral brasileiro. Rio de Janeiro: Jorge Zahar, 2000

GOHN, Maria da Glória. Educação não formal e cultura política: impactos sobre o associativismo do terceiro setor. 5. Ed. São Paulo: Cortez, 2011. (Coleção questões da nossa época, v.1).

KRASILCHIK, Myrian; MARANDINO, Martha. Ensino de Ciências e Cidadania. 2. ed. São Paulo: Moderna, 2007. 87 p. (Cotidiano Escolar Ação Docente).

MARANDINO, M. et al. A educação não formal e a divulgação científica: o que pensa quem faz? In: Encontro Nacional de Pesquisa em Educação em Ciências, IV, 2003, Bauru. Anais do IV ENPEC. São Paulo: Sociedade Brasileira de Física, p. 0113, 2003.

MORIN, Edgar. A cabeça bem-feita: repensar a reforma, reformar o pensamento. Tradução Eloá Jacobina. 8a ed. Rio de Janeiro: Bertrand Brasil, 2003. $128 p$. 
OLIVEIRA, Marta Kohl de. Vygotsky: Aprendizado e Desenvolvimento um Processo Sócio Histórico. 4. ed. São Paulo: Scipione, 2008. 111 p. (Pensamento e Ação no Magistério).

OLIVEIRA, Alana Priscila Lima de; CORREIA, Monica Dorigo. Aula de campo como mecanismo facilitador do ensino aprendizagem sobre ecossistemas recifais em Alagoas. Revista de Educação em ciências e tecnologia. V.6, p163-190, junho, 2013

OLIVEIRA, Roni Ivan Rocha; GASTAL, Maria Luiza de Araújo. Educação formal fora da sala de aula olhares sobre o ensino de ciências utilizando espaços não formais. Encontro Nacional de Ensino de Ciências, In: VII ENPEC, 2009 Anais... São Paulo, ABRAPEC

SANTOS, Maria do Carmo Pereira; BEZERRA, Hannah Priscila Alves; FIRMINO, Andressa Raiani de Souza; RANGEL, Jane. O incentivo das aulas de campo no ensino de geociências. Revista Novo enfoque, v.17, n17, p. 94-99, 2013

SCALCON, Suze. À Procura da Unidade Psicopedagógica: Articulando a psicologia histórico-cultural com a pedagogia histórico-crítica. Campinas: Autores Associados, 2002

SENICIATO, Tatiana; CAVASSAN, Oscar. Aula de campo em ambientes naturais e aprendizagem em ciências: um estudo com alunos de ensino fundamental.

Ciências e Educação, v.10, n1, p133-147, 2004

SILVA, Juliana Santana Ribeiro; SILVA, Mírian Berlamindo; VAREJÃO, José Leonídeo. Os (des)caminhos da educação: a importância do trabalho de campo na geografia. Vértices, Campos dos Goytacazes/RJ, v. 12, n.3, p.187-197, set/dez 2010.

TRILLA, J. A educação não formal. In: ARANTES; Valéria Amorim (Org.). Educação formal e não formal. São Paulo: Summus, 2008.

VYGOTSKY, Liev Semiónovitch. Pensamento e linguagem. São Paulo: Martins Fontes, 2005.

VYGOTSK,. Liev Semiónovitch. Formação social da mente. São Paulo: Martins Fontes. 2007 campo no ensino de ciências: reflexões a partir das perspectivas de professores. 
In: NARDI, R. org. Ensino de ciências e matemática. São Paulo: Editora UNESP; São Paulo: Cultura Acadêmica, 2009.

Recebido: 2015-06-23

Aprovado: 2017-02-07

DOI: $10.3895 /$ rbect.v10n2.3020

Como citar: FALK, J. E. W. M.; CARVALHO, M. P.; JESUS, T. B.; KRAUZER, K. A. F.; CAMPOS, C. R.

Aprendendo ciências e matemática em um sítio arqueológico sob diversos olhares: das práticas de ensino ao ensino das práticas. Revista Brasileira de Ensino de Ciência e Tecnologia, v. 10, n. 2, 2017. Disponível em: $<$ https://revistas.utfpr.edu.br/rbect/article/view/3020>. Acesso em: xxx.

\section{Correspondência:}

Direito autoral: Este artigo está licenciado sob os termos da Licença Creative Commons-Atribuição 4.0 Internacional.

\section{(c) (1)}


